\title{
Review
}

\section{Rapamycin and mTOR-independent autophagy inducers ameliorate toxicity of polyglutamine- expanded huntingtin and related proteinopathies}

\author{
S Sarkar ${ }^{1}$, B Ravikumar ${ }^{1}$, RA Floto ${ }^{2}$ and DC Rubinsztein ${ }^{*, 1}$
}

The formation of intra-neuronal mutant protein aggregates is a characteristic of several human neurodegenerative disorders, like Alzheimer's disease, Parkinson's disease (PD) and polyglutamine disorders, including Huntington's disease (HD). Autophagy is a major clearance pathway for the removal of mutant huntingtin associated with HD, and many other disease-causing, cytoplasmic, aggregate-prone proteins. Autophagy is negatively regulated by the mammalian target of rapamycin (mTOR) and can be induced in all mammalian cell types by the mTOR inhibitor rapamycin. It can also be induced by a recently described cyclical mTOR-independent pathway, which has multiple drug targets, involving links between $\mathrm{Ca}^{2+}-$ calpain- $\mathrm{G}_{\mathrm{s} \alpha}$ and $\mathrm{cAMP}-$ Epac-PLC- $\varepsilon-\mathrm{IP}_{3}$ signalling. Both pathways enhance the clearance of mutant huntingtin fragments and attenuate polyglutamine toxicity in cell and animal models. The protective effects of rapamycin in vivo are autophagy-dependent. In Drosophila models of various diseases, the benefits of rapamycin are lost when the expression of different autophagy genes is reduced, implicating that its effects are not mediated by autophagy-independent processes (like mild translation suppression). Also, the mTORindependent autophagy enhancers have no effects on mutant protein clearance in autophagy-deficient cells. In this review, we describe various drugs and pathways inducing autophagy, which may be potential therapeutic approaches for HD and related conditions.

Cell Death and Differentiation (2009) 16, 46-56; doi:10.1038/cdd.2008.110; published online 18 July 2008

\begin{abstract}
Autophagy
Macroautophagy (henceforth referred to as autophagy) has become a field of rapidly growing interest in recent years, and has possible implications in several human diseases such as cancer, certain neurodegenerative disorders, myopathies and infectious diseases. ${ }^{1}$ Autophagy is a non-specific, bulk degradation process involved in the clearance of long-lived proteins and organelles (Figure 1). The process begins with the formation of isolation membranes called phagophores at the phagophore assembly site. The phagophores then elongate and engulf a portion of the cytosol to form mature autophagosomes, which ultimately fuse with lysosomes to
\end{abstract}

form the degradative autophagolysosomes. ${ }^{2}$ Hybrid intermediates called amphisomes are formed when autophagosomes fuse with the endosomes. ${ }^{3}$ The acidic lysosomal hydrolases aid in the degradation of the engulfed contents and the nutrients are recycled back to the cell. ${ }^{2}$

Autophagy is a highly conserved process from yeast to mammals. Genetic analysis in yeast has uncovered several Atg (autophagy) genes, many of which have mammalian orthologs. ${ }^{4}$ The formation of yeast autophagosomes requires the Atg9p and its cycling system, a phosphatidylinositol 3-kinase (PI3K) complex and two ubiquitin-like conjugation systems. $^{2,5}$ The formation of autophagosome precursors requires class III PI3K and is prevented by PI3K inhibitors

\footnotetext{
${ }^{1}$ Department of Medical Genetics, University of Cambridge, Cambridge Institute for Medical Research, Addenbrooke's Hospital, Hills Road, Cambridge CB2 OXY, UK and ${ }^{2}$ Department of Medicine, University of Cambridge, Cambridge Institute for Medical Research, Addenbrooke's Hospital, Hills Road, Cambridge CB2 OXY, UK *Corresponding author: DC Rubinsztein, Department of Medical Genetics, University of Cambridge, Cambridge Institute for Medical Research, Addenbrooke's Hospital, Hills Road, Cambridge CB2 OXY, UK. Tel: + 441223762 608; Fax: + 441223331 206; E-mail: dcr1000 @ hermes.cam.ac.uk Keywords: autophagy; Huntington's disease; rapamycin

Abbreviations: AC, adenylyl cyclase; AD, Alzheimer's disease; ALS, amyotrophic lateral sclerosis; $\alpha_{2}-A R, \alpha_{2}$-adrenergic receptor; cAMP, cyclic AMP; CBZ, carbamazepine; CMA, chaperone-mediated autophagy; DAG, diacylglycerol; $2^{\prime} 5^{\prime} \mathrm{ddA}, 2^{\prime} 5^{\prime}$-dideoxyadenosine; ER, endoplasmic reticulum; FIP200, focal adhesion kinase family interacting protein of 200 kDa; FKBP12, FK506-binding protein 12; G $\beta$ L, G-protein $\beta$-subunit like protein; GSK-3 $\beta$, glycogen synthase kinase-3 $\beta$; HAP1A, huntingtin-associated protein-1A; HD, Huntington's disease; hsc70, heat shock cognate protein of $70 \mathrm{kDa}$; IMPase, inositol monophosphatase; Ins, inositol; IP $\mathrm{P}_{3}$, inositol 1,4,5-trisphosphate; $I P_{4}$, inositol 1,3,4,5-tetrakisphosphate; $I P_{3} R$, IP 3 receptor; I1R, inidazoline-1 receptor; LAMP2A, lysosome-associated membrane protein type 2A; 3 MA, 3-methyladenine; MAP1-LC3, microtubule-associated protein 1 light chain 3; MEF, mouse embryonic fibroblast; mGluR1/5, class 1 metabotropic glutamate receptor; mhtt, mutant huntingtin; mTOR, mammalian target of rapamycin; NMDAR, $N$-methyl-D-aspartate receptors; PACAP, pituitary adenylyl cyclase-activating polypeptide; PAS, phagophore assembly site; PD, Parkinson's disease; PI3K, phosphatidylinositol 3-kinase; $\mathrm{PIP}_{2}$, phosphatidylinositol 4,5-bisphosphatelPKA, protein kinase A; PLC, phospholipase C; polyA, polyalanine; polyQ, polyglutamine; raptor, regulatory associated protein of mTOR; SBMA, spinobulbar muscular atrophy; SCA, spinocerebellar ataxias; SMER, small-molecule enhancer of rapamycin; SMIR, small-molecule inhibitor of rapamycin; SOD1, superoxide dismutase 1; TSC, tuberous sclerosis complex; ULK, UNC (uncoordinated movement)-51-like kinase; VPA, valproic acid
}

Received 30.5.08; revised 18.6.08; accepted 18.6.08; Edited by G Kroemer; published online 18.7.08 


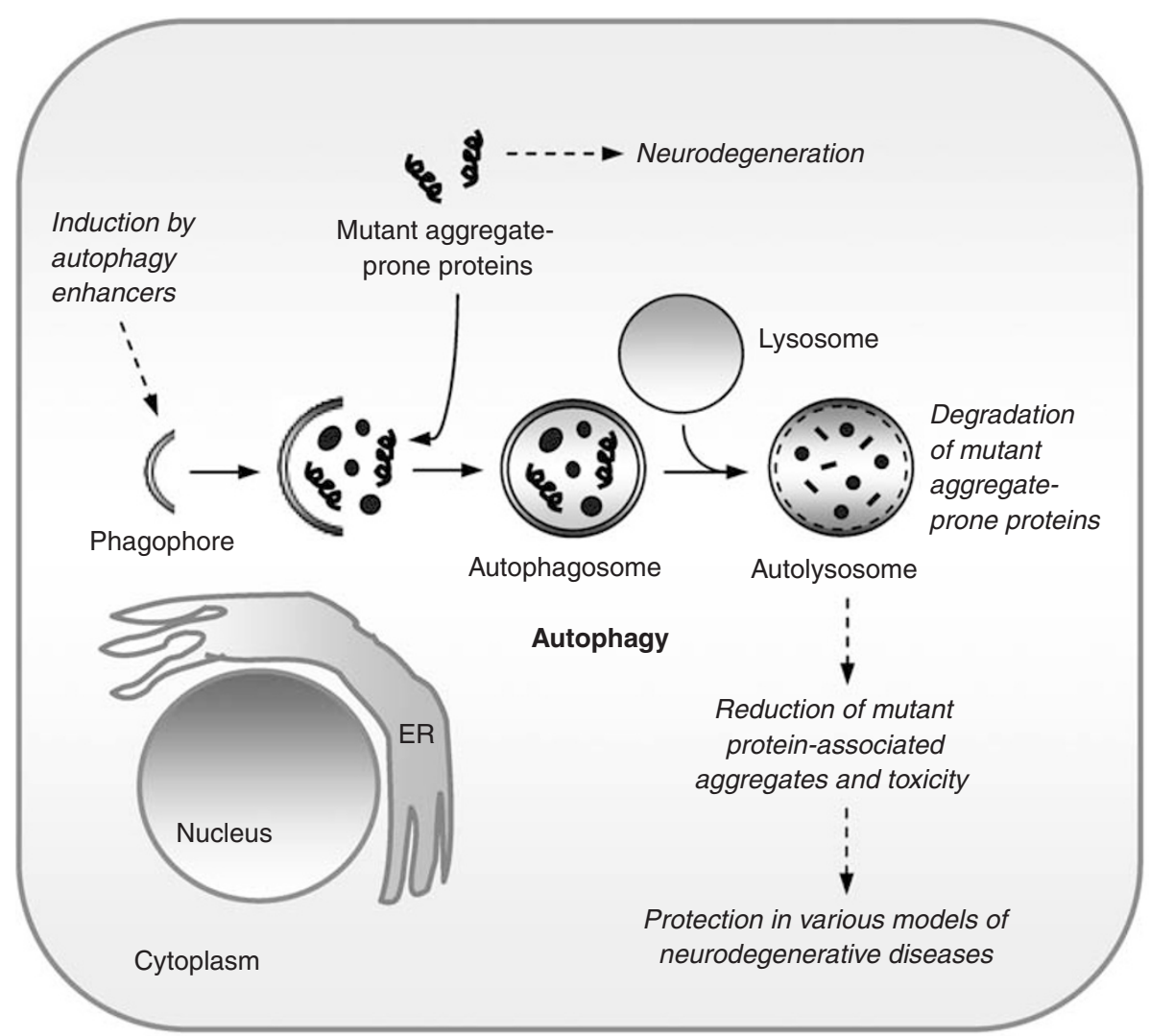

Figure 1 Autophagy as a protective pathway for the clearance of aggregate-prone proteins. Autophagy is one of the primary degradation pathways for various aggregateprone proteins associated with neurodegenerative diseases. Induction of autophagy by an autophagy enhancer triggers formation of double-membrane, cytoplasmic structures called phagophores, which engulf mutant aggregate-prone proteins along with portions of the cytoplasm within autophagosomes. Autophagosomes then ultimately fuse with the lysosomes to form autolysosomes, where their contents are degraded by acidic lysosomal hydrolases. This enhanced autophagic clearance of the mutant aggregate-prone proteins causing neurodegeneration results in a reduction in mutant protein-associated aggregation and toxicity, which is protective in several models of neurodegenerative diseases

like 3-methyladenine (3-MA) or wortmanin. ${ }^{6,7}$ The only known mammalian protein that specifically associates with the autophagosome membrane is LC3 (microtubule-associated protein 1 light chain 3), which is the mammalian ortholog of yeast Atg8p. Two forms of LC3 have been described: the cytosolic LC3-I form that conjugates with phosphatidylethanolamine upon autophagy induction, resulting in the autophagosome-associated LC3-II form. ${ }^{8}$

Similar to yeast, the classical pathway that regulates autophagy involves the serine/threonine kinase, mammalian target of rapamycin (mTOR). ${ }^{7}$ However, several pathways seem to regulate autophagy in mammalian cells. Physiologically, autophagy is induced by amino acid deprivation. ${ }^{9}$ Although yeast cells induce autophagy during nutrient deprivation conditions, autophagy occurs at a basal level in mammalian cells. Although autophagy is thought to be predominantly a cell survival mechanism, a number of studies also implicate a role for autophagy in cell death. ${ }^{10}$

\section{Aggregate-Prone Proteins Causing Neurodegeneration are Degraded by Autophagy}

The formation of mutant protein aggregates is a characteristic feature of several human neurodegenerative disorders, like Alzheimer's disease, Parkinson's disease (PD), amyotrophic lateral sclerosis (ALS), prion diseases and polyglutamine (polyQ) disorders, including Huntington's disease (HD) and various spinocerebellar ataxias (SCA).$^{11} \mathrm{It}$ is debated whether the aggregates are toxic or protective; however, recent studies have implicated the pre-aggregate oligomers to be the most toxic species. ${ }^{11-14}$ Experiments in cell culture have suggested that cells with large mutant huntingtin inclusions visible by light microscopy may be less prone to cell death than cells with diffuse mutant protein expression (which may however be present in microaggregates). ${ }^{15}$ However, this study did not test if cells with mutant huntingtin inclusions were compromised compared with cells overexpressing wild-type huntingtin. Although the monomeric aggregate-prone proteins can be cleared by the ubiquitin-proteasome system, the narrow pore of the proteasome precludes entry of oligomers and larger structures. As autophagy involves degradation of protein complexes and organelles, and the aggregates occurring in PD and HD visible by light microscopy are not membrane-bound and are larger than typical autophagosomes, it is likely that the monomeric and oligomeric species of the aggregate-prone proteins are cleared by autophagy. ${ }^{16}$

Autophagy is a major degradation pathway for various intracytosolic, aggregate-prone, disease-causing proteins associated with neurodegenerative disorders, such as mutant huntingtin (both $\mathrm{N}$-terminal fragments and full-length forms) 
associated with $\mathrm{HD}$, the A53T or A30P point mutants of $\alpha$-synuclein causing familial PD, ataxin 3 involved in SCA3, mutant forms of superoxide dismutase 1 causing familial ALS and mutant forms of tau causing fronto-temporal dementias. ${ }^{17-22}$

Another lysosomal pathway that may clear certain aggregate-prone proteins related to disease is chaperone-mediated autophagy (CMA). This pathway involves recognition of a pentapeptide motif in client proteins by cytosolic heat-shock cognate protein of $70 \mathrm{kDa}$ (hsc70), which mediates their ability to be taken up into lysosomes for degradation by the lysosome-associated membrane protein type 2A (LAMP2A) that acts as a receptor. This pathway appears to be important for the clearance of wild-type $\alpha$-synuclein. ${ }^{23}$ However, Cuervo et al. $^{23}$ have shown that dopamine-modified or the pointmutated forms of $\alpha$-synuclein cannot be cleared by this pathway - in fact these $\alpha$-synuclein species impaired the clearance of other CMA substrates. ${ }^{24}$

Recent studies by Mizushima, Tanaka and coworkers ${ }^{25,26}$ have highlighted a strong link between autophagy and neurodegeneration, as loss of basal autophagy by conditional knockout of key autophagy genes (Atg5 or Atg7) in mouse brains resulted in a neurodegenerative phenotype and the formation of protein aggregates. Thus, constitutive autophagy may play a pivotal role in the clearance of normally occurring misfolded proteins in the cells. We have previously shown that autophagy upregulation may be a possible therapeutic strategy for neurodegenerative diseases by enhancing the clearance of aggregate-prone proteins ${ }^{7}$ (Figure 1). In this review, we discuss various strategies for inducing autophagy, both by mTOR-dependent and -independent pathways (Table 1). These were identified using cell-based assays,

Table 1 List of autophagy enhancers and their protective effects in neurodegenerative diseases

\begin{tabular}{ll}
\hline Autophagy enhancer & Mode of action \\
\hline (1) Rapamycin & Inhibit mammalian target \\
(2) CCl-779 & of rapamycin (mTOR) \\
(3) Glucose & \\
(4) Glucose-6-phosphate &
\end{tabular}

Protective effects in neurodegenerative diseases

Enhance clearance of mutant htt (1-4), $\alpha$-syn $(1,3,4)$, tau (1), ataxin 3 (1) and expanded polyA (1); reduce mutant htt (1-4) and expanded polyQ (1) aggregates; inhibit intrinsic apoptotic pathway (1); protect cell (1-4), fly (1) and mouse models (2) of HD; protect fly models of tauopathy (1), SBMA (1) and flies with expanded polyQ or polyA (1)

Enhance clearance of mutant htt and $\alpha$-syn $(5,6)$; reduce mutant htt $(5,6)$ and SOD1 (5) aggregates; protect cell $(5,6)$ and fly models of HD $(5)$; protect and increase survival in ALS mouse models and patients (5)

Enhance clearance of mutant htt and $\alpha$-syn $(7,8)$; reduce mutant htt aggregates $(7,8)$; protect cell $(7,8)$ and fly (8) models of HD

Enhance clearance of mutant htt and $\alpha$-syn (9-13); reduce mutant htt (9-13) and expanded polyQ $(10,11$, $14,15)$ aggregates; protect cell (9-13), fly (9) and zebrafish (9) models of HD

(10) Loperamide

(11) Amiodarone

(12) Nimodipine

(13) Nitrendipine

(14) Niguldipine

(15) Pimozide

(16) Calpastatin

(17) Calpeptin

(18) Clonidine

(19) Rilmenidine

(20) 2'5'-dideoxyadenosine

(21) NF449

(22) Minoxidi

(23) Penitrem A

(24) Fluspiriline

(25) Trifluoperazine

(26) Trehalose

Lower inositol and $\mathrm{IP}_{3}$ levels; mTOR-independent

$\mathrm{Ca}^{2+}$ channel blocker; mTOR-independent

Calpain inhibitor: mTOR-independent

Imidazoline-1 receptor agonist; reduce CAMP mTOR-independent

Adenylyl cyclase inhibitor; reduces CAMP

mTOR-independent

$\mathrm{G}_{\mathrm{s} \alpha}$ inhibitor; mTOR-independent

$\mathrm{K}_{\text {ATP }}^{+}$channel opener;

mTOR-independent

Inhibits high conductance

$\mathrm{Ca}^{2+}$-activated $\mathrm{K}^{+}$channel;

mTOR-independent

Dopamine antagonist;

mTOR-independent

Unknown; mTOR-independent

(27) SMER10

(28) SMER18

Unknown; mTOR-independent
Enhance clearance of mutant htt and $\alpha$-syn $(16,17)$; reduce mutant htt aggregates $(16,17)$; protect cell $(16$ 17) and zebrafish (16) models of HD

Enhance clearance of mutant htt and $\alpha$-syn $(18,19)$;

reduce mutant htt aggregates $(18,19)$; protect cell $(18$, $19)$, fly (18) and zebrafish (18) models of HD

Enhances clearance of mutant htt and $\alpha$-syn; reduces mutant htt aggregates; protects cell and zebrafish models of HD (20)

Reduces mutant htt aggregates in cells (21)

Enhances clearance of htt and $\alpha$-syn; reduces mutant

htt aggregates; protects cell models of HD (22)

Reduces expanded polyQ aggregates in cells (23)

Reduce expanded polyQ aggregates in cells $(24,25)$

Enhances clearance of mutant htt and $\alpha$-syn; reduces mutant htt aggregates; inhibits intrinsic apoptotic pathway; protects cell and mouse models of HD (26)

Enhance clearance of mutant htt and $\alpha$-syn (27-30); reduce mutant htt aggregates (27-30); protect cell and fly models of HD (27-29)
Reference

$17-20,27-29$

(30) 18 SMER analogues

ALS, amyotrophic lateral sclerosis; $\alpha$-syn, $\alpha$-synuclein; camp, cyclic AMP; HD, Huntington's disease; htt, Huntingtin; IMPase, inositol monophosphatase; IP 3 , inositol 1,4,5-trisphosphate; mTOR, mammalian target of rapamycin; polyA, polyalanine; polyQ, polyglutamine; SBMA, spinobulbar muscular atrophy; SOD1, superoxide dismutase 1; SMER, small molecule enhancer of rapamycin 
either by measuring the clearance of autophagy substrates or by analysing autophagic flux.

\section{Rapamycin Attenuates Toxicity of Aggregate-prone Proteins by Enhancing Autophagy, with Minimal Influence via Autophagy-independent Effects Like Translation}

Autophagy is negatively regulated by mTOR, whose activity can be inhibited by rapamycin, a lipophilic macrolide antibiotic that is a well-established inducer of autophagy ${ }^{37}$ (Figure 2). The mTOR pathway involves two functional complexes: mTORC1 consisting of mTOR, raptor (regulatory associated protein of $\mathrm{mTOR}$ ) and $\mathrm{G} \beta \mathrm{L}$ (G-protein $\beta$-subunit like protein); and mTORC2 comprising mTOR, rictor and $\mathrm{G} \beta \mathrm{L} .{ }^{38}$ Rapamycin forms a complex with the immunophilin FK506-binding protein 12 (FKBP12), which then stabilizes the raptor-mTOR association and inhibits the kinase activity of mTOR. ${ }^{39}$ The binding of $\mathrm{G} \beta \mathrm{L}$ to mTOR stimulates its kinase activity, and $\mathrm{G} \beta \mathrm{L}$ is necessary for the formation of a rapamycin-sensitive interaction between raptor and mTOR. ${ }^{40}$ Rapamycin is a potent inducer of autophagy in a diverse range of cell lines from yeast to mammalian cells tested to date, including neuron-like cells. ${ }^{17,18,37,41}$ However, its downstream targets that regulate autophagy are still unknown in mammalian cells.

We have previously shown that rapamycin treatment in cells expressing several aggregate-prone mutant proteins, such as huntingtin, $\alpha$-synucleins, ataxin 3 and tau, enhanced the degradation of the target proteins and reduced the number of aggregates, and also protected cells and flies from mutant protein-associated toxicity. ${ }^{17-20}$ As mTOR regulates a number of cellular functions distinct from autophagy-like translation, ${ }^{38}$ it is important to test if the protective effects of this drug against aggregate-prone intracytosolic proteins are autophagy-dependent. This is not feasible in mice, but can be tested in Drosophila, where one can overexpress an aggregate-prone protein in the context of a wild-type genetic background or a genetic background where an autophagy gene is modified. The protective effect of rapamycin in these situations appear to be autophagy-dependent in vivo, because its ability to protect against the toxicity of a polyalanine (polyA)-expanded aggregate-prone protein (which was previously shown to be an autophagy substrate) was abolished in flies expressing the mutant protein on a genetic background with $50 \%$ loss of the key autophagy gene, Atg $1{ }^{20}$ This conclusion was reinforced by an independent subsequent study that showed that the ability of rapamycin to reduce the toxicity of a polyQ-expanded protein was abrogated in flies where a different autophagy gene (Atg12) was knocked down by RNAi. ${ }^{27}$ These studies strongly suggest that the protective effects of rapamycin in vivo are through autophagy, and that the effects of other consequences of rapamycin treatment, like inhibition of translation, ${ }^{42}$ are minimal. Consistent with the fly data, the rapamycin analogue $\mathrm{CCl}-779$ ameliorates and delays the onset of a range of behavioural abnormalities and reduces aggregate load in a mouse model of HD. ${ }^{18}$

Rapamycin and autophagy upregulation also protects cells against pro-apoptotic insults by clearing mitochondria, which are endogenous autophagy substrates. ${ }^{28}$ As a consequence of reduced mitochondrial load, the intrinsic apoptotic pathway was inhibited because of reduced cytochrome $c$ release,

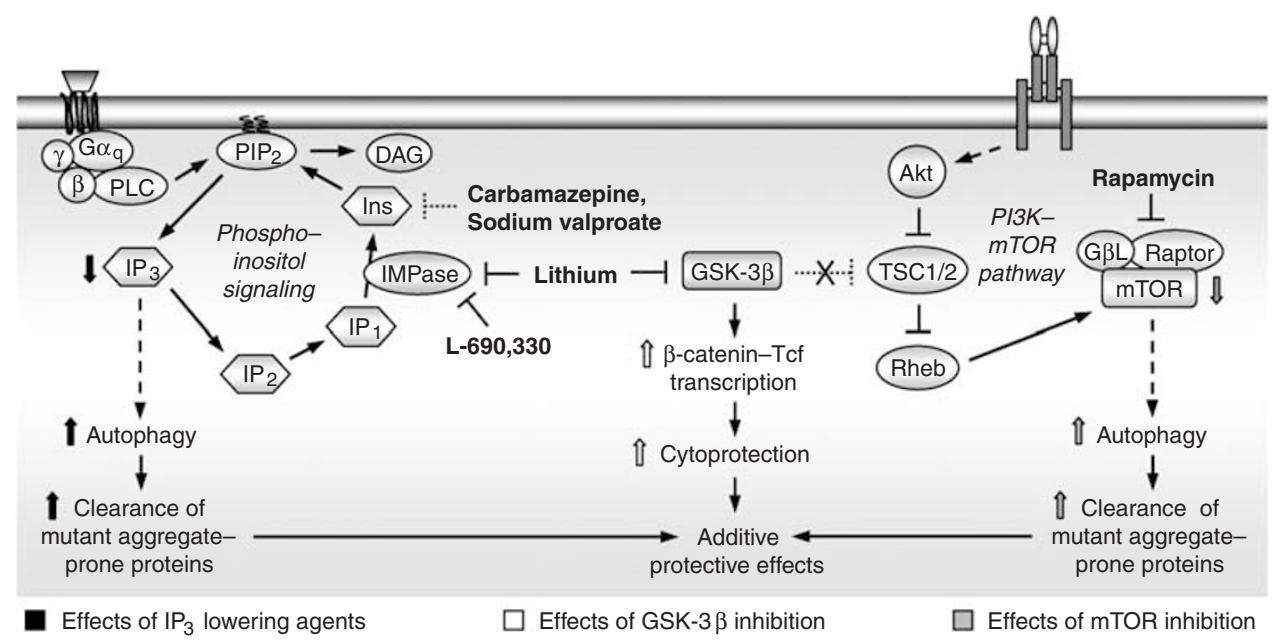

Figure 2 Combinatorial strategy for upregulating autophagy by mTOR and phospho-inositol-signalling pathways. The mammalian target of rapamycin (mTOR), which is a downstream target in the phosphatidylinositol 3-kinase (PI3K) pathway, negatively regulates autophagy. A diverse range of signals, such as growth factors and amino acids, regulate the raptor-mTOR pathway by inhibiting tuberous sclerosis complex (TSC1/2), thereby alleviating the inhibitory effect of TSC1/2 on rheb, which subsequently activates the raptor-mTOR complex. Several kinases, such as Akt, signal to raptor-mTOR by phosphorylating TSC2 and inhibiting the activity of the TSC1/2 heterodimer. Rapamycin forms a complex with the immunophilin FK506-binding protein 12 (FKBP12), which then stabilizes the raptor-mTOR association and inhibits the kinase activity of mTOR. Inhibition of mTOR by rapamycin induces autophagy and enhances the clearance of mutant aggregate-prone proteins associated with neurodegenerative diseases. Autophagy can also be induced with compounds that decrease inositol (Ins) or inositol 1,4,5-trisphosphate $\left(\mathrm{IP}_{3}\right)$ levels in the phosphoinositol-signalling pathway in an mTORindependent manner. These agents include lithium and L-690,330 by inhibiting inositol monophosphatase (IMPase), and carbamazepine and sodium valproate by inhibiting inositol synthesis. However, lithium also inhibits glycogen synthase kinase-3 $\beta$ (GSK-3 $\beta$ ) that activates mTOR by inhibiting TSC1/2, thereby impairing autophagy. Combination treatment with lithium and rapamycin alleviates the block in autophagy by GSK-3 $\beta$ inhibition (shown by a cross, $\mathrm{X}$ ), and hence additively enhances autophagy and facilitates greater clearance of the aggregate-prone proteins. Furthermore, GSK-3 $\beta$ inhibition by lithium increases $\beta$-catenin-Tcf-mediated transcription, which is cytoprotective and may contribute to additional protective effects of this combination treatment for neurodegenerative diseases. Colour-coded block arrows denote increase or decrease 
leading to decreased activation of caspases 9 and 3. Again, the protective effects of rapamycin in this context were autophagy-dependent and its benefits against paraquat toxicity in Drosophila were abrogated in flies with a $50 \%$ loss of $A \operatorname{tg} 1 .^{28}$ This anti-apoptotic effect of autophagy upregulation may be beneficial in neurodegenerative disorders where there are secondary apoptotic insults.

\section{An mTOR-Independent Pathway Regulating Autophagy Through Inositol or $\mathrm{IP}_{3}$ Levels}

We previously demonstrated that autophagy can be induced by lowering intracellular inositol or inositol 1,4,5-trisphosphate $\left(\mathrm{IP}_{3}\right)$ levels $^{30}$ (Figure 2). This was the first demonstration of the existence of an autophagy pathway in mammalian system independent of mTOR. Mood-stabilizing drugs for affective disorders, such as lithium, carbamazepine and sodium valproate, all of which reduce inositol levels, ${ }^{43}$ induced autophagy and enhanced the clearance of autophagy substrates, such as mutant huntingtin and the A53T and A30P mutants of $\alpha$-synuclein. ${ }^{30}$ On the contrary, increasing cellular inositol levels by myo-inositol or elevating $\mathrm{IP}_{3}$ levels by an inhibitor of prolyl oligopeptidase activity, ${ }^{43}$ retarded the clearance of autophagy substrates and abrogated the effects of lithium, but not of rapamycin. ${ }^{30}$ Moreover, drugs that decrease $\mathrm{IP}_{3}$ levels did not reduce mTOR activity, and rapamycin did not affect inositol levels, further suggesting that the control of autophagy by $\mathrm{IP}_{3}$ and rapamycin is mediated by two independent pathways. The autophagy-inducing ability of lithium was due to inhibition of inositol monophosphatase (IMPase), which prevents inositol recycling, leading to depletion of cellular inositol and inhibition of the phosphoinositol cycle. ${ }^{30,44,45}$ Likewise, L-690330, a specific IMPase inhibitor, induced autophagy and mimicked the effects of lithium on the clearance of autophagy substrates. ${ }^{30}$ Consistent with a role of $\mathrm{IP}_{3}$ on autophagy, a recent study by Kroemer and coworkers ${ }^{46}$ has shown that genetic knockdown or pharmacological inhibition of the $\mathrm{IP}_{3}$ receptor $\left(\mathrm{IP}_{3} \mathrm{R}\right)$ induces autophagy.

Although lithium has been used for decades for treating bipolar disorder patients, its mechanism of action is still not fully understood. Inositol depletion is one of the most widely accepted hypotheses for its therapeutic action. ${ }^{47}$ It is tempting to speculate whether the beneficial effects of inositol-lowering agents used in the treatment of bipolar disorder are mediated by the clearance of long-lived autophagy substrates (this does not implicate protein aggregation is a feature of this disease), as lithium has acute effects on free inositol levels before showing clinical effects. ${ }^{48}$ This idea ${ }^{48}$ has recently been followed up in a study that demonstrated antidepressant effects of rapamycin in rat and mouse models, leading to the suggestion that autophagy inducers may be helpful in the treatment of these disorders. ${ }^{49}$

The autophagy-inducing effects of lithium facilitated the clearance of mutant huntingtin in HD cell models, and reduced mutant protein-associated aggregation and toxicity. ${ }^{30}$ Lithium also reduced neurodegeneration in HD Drosophila models. ${ }^{31}$ However, lithium is likely to have various antiapoptotic effects by inhibiting another intracellular target, glycogen synthase kinase-3 $\beta$ (GSK-3 $\beta$ ), resulting in $\beta$-catenin upregulation. ${ }^{50-52}$
A recent study by Fornai and coworkers ${ }^{21}$ has shown a striking effect of lithium in increasing survival and attenuating the disease progression in ALS patients and mouse models. All the ALS patients on lithium treatment for 15 months survived, but approximately $30 \%$ of age-, disease durationand sex-matched controls receiving riluzole died. ${ }^{21}$ Apart from lithium's neuroprotective effects, ${ }^{50}$ this fascinating result was suggested to be at least partially due to induction of autophagy. ${ }^{21}$ Importantly, the above study also demonstrated that lithium can trigger autophagy in neurons. ${ }^{21}$ Consistent with the protective role of $\mathrm{IP}_{3}$-lowering agents through autophagy induction, sodium valproate, which inhibits inositol synthesis and thereby decreases intracellular $\mathrm{IP}_{3}$ levels, ${ }^{43,53}$ also protected against neurodegeneration in a Drosophila model of HD. ${ }^{32}$

\section{Combination Treatment for Enhancing Autophagy by mTOR-Dependent and -Independent Pathways}

The availability of mTOR-dependent and -independent pathways allows for a combination treatment strategy that enables greater upregulation of autophagy by simultaneously inducing autophagy using both rapamycin and lithium ${ }^{31}$ (Figure 2). Apart from the ability of lithium to induce mTOR-independent autophagy by inhibiting IMPase, ${ }^{30}$ GSK-3 $\beta$, another intracellular target of lithium, has opposing effects on autophagy in an mTOR-dependent fashion. ${ }^{31}$ Guan and coworkers ${ }^{54}$ reported inhibition of GSK-3-activated mTOR signalling by preventing GSK-3-dependent phosphorylation of tuberous sclerosis complex (TSC) protein TSC2. As activation of mTOR negatively regulates autophagy, we confirmed that autophagy was impaired by a specific GSK-3 $\beta$ inhibitor, SB216763, or in GSK-3 $\beta$-deficient mouse embryonic fibroblasts (MEFs) compared with the wild-type MEFs. ${ }^{31}$ Inhibition of GSK-3 $\beta$ retarded the clearance of aggregate-prone proteins, whereas a constitutively active GSK-3 $\beta$ enhanced clearance and autophagic flux. To counteract the autophagy-inhibitory effects of mTOR activation resulting from lithium treatment because of GSK-3 $\beta$ inhibition, we used rapamycin in combination with lithium. Rapamycin abrogates the mTOR activation mediated by lithium and the combination allows autophagy stimulation by mTOR inhibition and by lowering of $\mathrm{IP}_{3}$ levels. Combination treatment with lithium and rapamycin had additive protective effects on the autophagic clearance of mutant huntingtin and against cell death, compared with the effects of either drug alone. ${ }^{30,31}$ We have further demonstrated proof-of-principle for this rational combination treatment approach in vivo by showing greater protection against neurodegeneration in an HD Drosophila model with TOR inhibition and lithium, or in HD flies treated with rapamycin and lithium, compared with inhibition of either pathway alone. ${ }^{31}$ Moreover, this strategy may also benefit from the cytoprotective effects of GSK-3 $\beta$ inhibition, because of activation of the $\beta$-catenin/Tcf pathway ${ }^{31,51,52}$ (Figure 2).

The rationale for enhancing autophagy using the modulators of mTOR-dependent and mTOR-independent pathways is also seen by the use of saturating doses of rapamycin with other mTOR-independent autophagy inducers that have been subsequently identified. ${ }^{30,32,34,36}$ Such combination treatments greatly facilitate the clearance of aggregate-prone 
proteins and reduce toxicity in cell models, compared with either compounds alone. Combination therapy with lower doses of each drug may be safer for long-term treatment and may lessen the drug-specific side-effects if used for neurodegenerative diseases, compared with using doses of either compound alone that result in more severe perturbations of a single pathway. However, demonstration of this combination treatment strategy in mouse models of neurodegenerative disorders is challenging and remains to be investigated.

\section{An mTOR-Independent Cyclical Autophagy Pathway with Multiple Drug Targets}

Apart from the classical mTOR pathway regulating mammalian autophagy, we have recently described many of the players in an mTOR-independent pathway ${ }^{32}$ (Figure 3). We screened for autophagy modulators with 253 FDA-approved drugs and pharmacological probes by assessing the clearance of autophagy substrates, such as the A30P and A53T mutants of $\alpha$-synuclein and mutant huntingtin. This screen yielded various autophagy enhancers, such as L-type $\mathrm{Ca}^{2+}$ channel antagonists, a $\mathrm{K}_{\mathrm{ATP}}^{+}$channel opener and a $\mathrm{G}_{\mathbf{i}^{-}}$ signalling activator, whose mechanisms of action were found to be linked in a cyclical fashion. The L-type $\mathrm{Ca}^{2+}$ channel modulators regulate autophagy by influencing intracytosolic $\mathrm{Ca}^{2+}$ levels, thereby regulating calpain activity, which in turn regulates the cleavage and activity of $G_{s \alpha}$ that subsequently generates cyclic AMP (CAMP). The $\mathrm{K}_{\text {ATP }}^{+}$channel opener reduces cytosolic $\mathrm{Ca}^{2+}$ levels (like the L-type $\mathrm{Ca}^{2+}$ channel blockers) and is likely to work by the same pathway. On the other hand, the $\mathrm{G}_{\mathrm{i}}$-signalling activator reduces cAMP, which regulates phospholipase C- $\varepsilon$ (PLC- $\varepsilon$ ) activity through the Epac pathway, thereby influencing the generation of $\mathrm{IP}_{3}$, which subsequently regulates calpain activity. ${ }^{32}$ The data from this screen was consistent with previous findings where lowering intracellular $\mathrm{IP}_{3}$ levels triggered autophagy. ${ }^{30}$ This cyclical autophagy pathway has multiple drug targets for chemically inducing autophagy, and drugs acting on this pathway were protective in cell, Drosophila and zebrafish models of $\mathrm{HD}^{32}$ (Figure 3). The mTOR-independent autophagy enhancers identified in our screen may be of importance for neurodegenerative diseases like HD or other conditions where autophagy acts as a protective pathway. We will discuss the two arms of the pathway $\left(\mathrm{Ca}^{2+}\right.$-calpain- $\mathrm{G}_{\mathrm{s} \alpha}$ pathway and cAMP-Epac-PLC- $\varepsilon-\mathrm{IP}_{3}$ pathway) separately.

Regulation of autophagy by $\mathrm{Ca}^{2+}-$ calpain- $\mathbf{G}_{\mathbf{s} \alpha}$ pathway. The regulation of autophagy by intracytosolic $\mathrm{Ca}^{2+}$ levels was first suggested by Seglen and coworkers $^{55}$ more than a decade ago. The data from our recent screen was consistent with their earlier findings, in which an increase in intracytosolic $\mathrm{Ca}^{2+}$ was found to inhibit autophagy in rat hepatocytes. They found that autophagy was inhibited with agents like thapsigargin (an endoplasmic reticulum (ER) $\mathrm{Ca}^{2+} / \mathrm{Mg}^{2+}$ ATPase inhibitor that releases $\mathrm{Ca}^{2+}$ from ER stores) or ionomycin $\left(\mathrm{Ca}^{2+}\right.$ ionophore that releases $\mathrm{Ca}^{2+}$ from intracellular stores), which increase intracytosolic $\mathrm{Ca}^{2+}$ levels. ${ }^{55}$

The first category of compounds that our screen revealed as autophagy enhancers are L-type $\mathrm{Ca}^{2+}$ channel

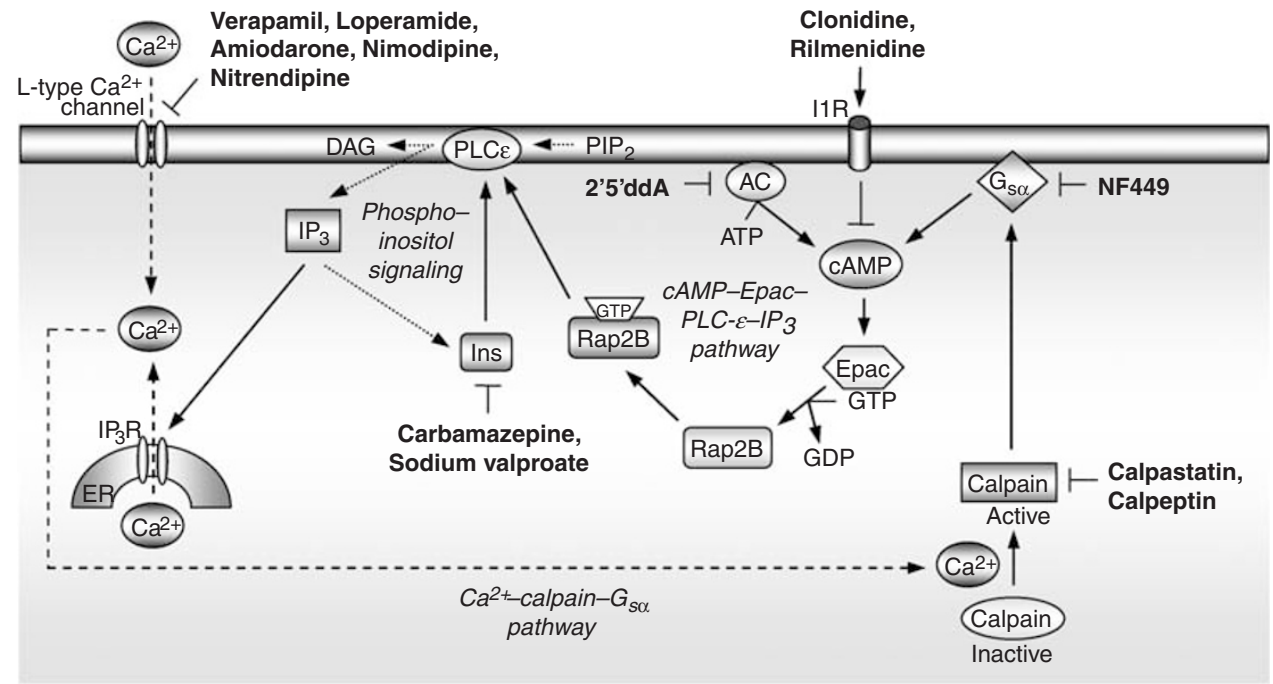

Figure 3 A cyclical mTOR-independent autophagy pathway. A cyclical mTOR-independent pathway regulating mammalian autophagy, comprising cAMP-Epac-PLC- - $\mathrm{IP}_{3}$ and $\mathrm{Ca}^{2+}$-calpains- $\mathrm{G}_{\mathrm{s} \alpha}$ pathways, which has multiple drug targets for neurodegenerative diseases. Intracellular cAMP levels are increased by adenylyl cyclase (AC) activity, thereby activating Epac. Epac then activates a small G-protein Rap2B, which activates PLC- $\varepsilon$, resulting in the production of $\mathrm{IP}_{3}$ consequently releasing $\mathrm{Ca}^{2+}$ from the endoplasmic reticulum (ER) stores. Intracytosolic $\mathrm{Ca}^{2+}$ levels are also increased by L-type $\mathrm{Ca}^{2+}$ channel agonists. An increase in intracytosolic $\mathrm{Ca}^{2+}$ activates a family of

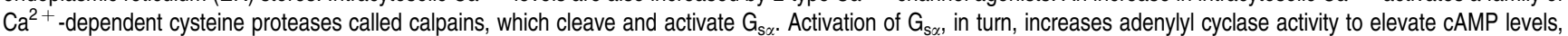
thereby forming a loop. Activation of this pathway inhibits autophagy. Multiple drug targets acting at distinct stages in this pathway induce autophagy, such as imidazoline-1 receptor (I1R) agonists (clonidine and rilmenidine) and adenylyl cyclase inhibitor $\left[2^{\prime} 5^{\prime}\right.$-dideoxyadenosine $\left.\left(2^{\prime} 5^{\prime} \mathrm{ddA}\right)\right]$, which decrease the levels of intracellular cAMP, agents reducing inositol and $\mathrm{IP}_{3}$ levels [carbamazepine (CBZ) and valproic acid (VPA)], L-type $\mathrm{Ca}^{2+}$ channel antagonists (verapamil, loperamide, amiodarone, nimodipine and nitrendipine), calpain inhibitors (calpastatin and calpeptin) and $\mathrm{G}_{\mathrm{s} \alpha}$ inhibitor (NF449). Upregulating autophagy through this pathway has been shown to be protective in cell, fly and zebrafish models of Huntington's disease (HD) 
antagonists, such as verapamil, loperamide, amiodarone, nimodipine and nitrendipine ${ }^{32}$ (Figure 3 ). These compounds prevent the influx of extracellular $\mathrm{Ca}^{2+}$ by inhibiting the L-type $\mathrm{Ca}^{2+}$ channels on the plasma membrane, thereby decreasing intracytosolic $\mathrm{Ca}^{2+}$ levels. Conversely, the L-type $\mathrm{Ca}^{2+}$ channel agonist ( \pm )-Bay K8644, which increases intracytosolic $\mathrm{Ca}^{2+}$, inhibited autophagy. The L-type $\mathrm{Ca}^{2+}$ channel antagonists enhanced the clearance of mutant aggregate-prone proteins and reduced mutant huntingtin aggregates in an autophagy-dependent manner, whereas the L-type $\mathrm{Ca}^{2+}$ channel agonist had opposite effects.

L-type $\mathrm{Ca}^{2+}$ channel antagonists, such as verapamil, have been used for treating hypertension for many years. ${ }^{56}$ This drug was previously shown by electron microscopy to increase the number of autophagosomes in rat myocardial tissues. ${ }^{57}$ Further to showing the effect of verapamil on autophagy in various cellular models, we also demonstrated that it protected against neurodegeneration in Drosophila and zebrafish models of $\mathrm{HD} .^{32}$ Whereas verapamil reduced mutant huntingtin aggregates in a zebrafish model of $\mathrm{HD}$, the L-type $\mathrm{Ca}^{2+}$ channel agonist ( \pm )-Bay K8644 increased aggregation. ${ }^{32}$ As verapamil has minimal side effects, it may be a potential therapeutic candidate for diseases where autophagy acts as a protective pathway.

Some of the L-type $\mathrm{Ca}^{2+}$ channel antagonists found in our screen as autophagy inducers were also reported by Yuan and coworkers ${ }^{33}$ in an independent screen where the number of GFP-LC3 vesicles was measured as readout. The $\mathrm{Ca}^{2+}$ channel blockers from their screen, such as loperamide, amiodarone, niguldipine and pimozide, also reduced polyQ aggregates in cell models by inducing autophagy independently of mTOR. ${ }^{33}$

Another class of compounds obtained from our recent screen that modulate cytosolic $\mathrm{Ca}^{2+}$ levels are $\mathrm{K}_{\mathrm{ATP}}^{+}$channel openers, such as minoxidil. ${ }^{32}$ Minoxidil decreases whole-cell L-type $\mathrm{Ca}^{2+}$ channels, ${ }^{58}$ induces autophagy and promotes the clearance of autophagy substrates. ${ }^{32}$ Our screen also revealed some $\mathrm{K}_{\mathrm{ATP}}^{+}$channel blockers, such as quinine sulphate and tolazamide, which retarded the clearance of autophagy substrates, in contrast to minoxidil. ${ }^{32}$

An increase in intracytosolic $\mathrm{Ca}^{2+}$ activates a family of $\mathrm{Ca}^{2+}$-dependent cysteine proteases called calpains, including the ubiquitously-expressed calpain 1 ( $\mu$-calpain) and calpain 2 (m-calpain). ${ }^{59}$ Calpain activation by L-type $\mathrm{Ca}^{2+}$ channel agonists or overexpression of constitutively active $\mathrm{m}$-calpain inhibits autophagy and retards the clearance of aggregate-prone proteins. ${ }^{32}$ Likewise, inhibition of calpain by inhibitors such as calpastatin and calpeptin, or genetic knockdown, induces autophagy and enhances the clearance of autophagy substrates. Furthermore, calpastatin increased autophagic flux in cells and reduced mutant huntingtin aggregates in a zebrafish model of $\mathrm{HD}^{32}$ The effects of L-type $\mathrm{Ca}^{2+}$ channel antagonists or agonists were abolished in the presence of calpain activation or inhibition, respectively, suggesting that calpain is acting downstream of the autophagy-regulatory effects of free cytosolic $\mathrm{Ca}^{2+}$ levels ${ }^{32}$ (Figure 3).

Calpain activation inhibits autophagy by cleaving the $\alpha$-subunit of heterotrimeric G-proteins $\left(G_{s \alpha}\right),{ }^{32}$ whose activity increases leading to greater adenylyl cyclase activation and thus cAMP production. ${ }^{60}$ Chemical inhibition of $\mathrm{G}_{\mathrm{s} \alpha}$ with NF449 or with siRNA knockdown increased autophagic flux and enhanced the clearance of autophagy substrates. ${ }^{32}$ The autophagy-inhibitory effects of calpain activation were abolished by knockdown of $\mathrm{G}_{\mathrm{s} \alpha}$ with siRNA. On the other hand, activation of $G_{s \alpha}$ with its natural ligand, pituitary adenylyl cyclase-activating polypeptide (PACAP), retarded the clearance of autophagy substrates. The autophagy-inhibitory effect of PACAP was abolished by an adenylyl cyclase inhibitor $2^{\prime} 5^{\prime}$-dideoxyadenosine that reduces cAMP levels, but not by the calpain inhibitor calpastatin. ${ }^{32}$ This suggests that $\mathrm{G}_{\mathrm{s} \alpha}$ is a downstream mediator of calpain regulating autophagy, which creates a link between $\mathrm{Ca}^{2+}$-calpain and the cAMP pathway. Moreover, the autophagy-inhibitory effects of constitutively active $\mathrm{m}$-calpain were rescued by $2^{\prime} 5^{\prime}$-dideoxyadenosine, further suggesting that cAMP is a downstream target of calpain and $\mathrm{G}_{\mathrm{s} \alpha}{ }^{32}$ (Figure 3).

An apparent conflict with our data which suggests that cytosolic $\mathrm{Ca}^{2+}$ inhibits autophagy by activating calpains, may be found in a study that reported that elevations in the levels of intracytosolic $\mathrm{Ca}^{2+}$, after treatments with $\mathrm{Ca}^{2+}$-mobilizing agents like thapsigargin or ionomycin, induced autophagy. ${ }^{61}$ However, the authors measured only GFP-LC3 vesicle (autophagosome) numbers and the study lacked data on autophagic flux. Consistent with the autophagy-inhibitory effects of thapsigargin as reported previously by Seglen and coworkers, ${ }^{55}$ we found that thapsigargin actually inhibits autophagic flux by two different mechanisms. ${ }^{32}$ We found that thapsigargin increased LC3-II levels or LC3-positive vesicles (surrogates for autophagosome number), but that this was because of a block in autophagosome-lysosome fusion, rather than an increase in autophagosome synthesis. (These possibilities were distinguished by assessing autophagosome numbers under conditions where autophagosome degradation is inhibited.) Thapsigargin also inhibited autophagosome formation and retarded the clearance of autophagy substrates in an autophagy-dependent manner, which were largely rescued by calpain inhibition, consistent with our model and data suggesting that calpains are the main mediators of the autophagy-inhibitory effects of elevated intracytosolic $\mathrm{Ca}^{2+}$ levels. ${ }^{32}$ However, these data also suggest that thapsigargin may have complex effects on autophagy - some mediated by calpains (decreasing autophagosome synthesis) and some mediated by other effects (possibly by ER-related effects) resulting in impaired autophagsome-lysosome fusion.

Regulation of autophagy by cAMP-Epac-PLC- $-\mathrm{IP}_{3}$ pathway. Another category of autophagy enhancers that our recent screen revealed was a $\mathrm{G}_{\mathrm{i}}$-signalling activator clonidine, which reduces cAMP levels and thereby links with the $\mathrm{Ca}^{2+}$-calpain- $\mathrm{G}_{\mathrm{s} \alpha}$ pathway ${ }^{32}$ (Figure 3). Clonidine reduces cAMP levels by binding to $\alpha_{2}$-adrenergic $\left(\alpha_{2}-A R\right)$ receptors, thereby activating the $\mathrm{G}_{\mathrm{i}}$-signalling pathway and inhibiting adenylyl cyclase. ${ }^{62}$ It also lowers cAMP by binding to imidazoline-1 (I1R) receptors, ${ }^{63}$ but whether this is mediated through G-proteins is disputed. Our study revealed that clonidine was triggering autophagy by reducing cAMP levels through I1R. Likewise, rilmenidine, a clinically approved 
centrally acting drug that binds to $11 \mathrm{R}$ at a much greater affinity than to $\alpha_{2}$-AR, also induced autophagy and enhanced the clearance of mutant aggregate-prone proteins. ${ }^{32}$

Furthermore, agents that modulate cAMP levels, such as the adenylyl cyclase inhibitor $2^{\prime} 5^{\prime}$-dideoxyadenosine that reduces $\mathrm{CAMP}$, induced autophagy and enhanced the clearance of autophagy substrates; whereas CAMP activators like forskolin or cAMP analogues like dibutyryl cAMP had opposite effects. ${ }^{32}$ Consistent with our data, Ohsumi and $\mathrm{Noda}^{37}$ have previously shown that high levels of cAMP inhibited autophagy in yeast. The autophagy-inducing effects of clonidine and $2^{\prime} 5^{\prime}$-dideoxyadenosine protected against rod photoreceptor degeneration and reduced mutant huntingtin aggregates in a zebrafish model of HD. Clonidine also protected against neurodegeneration in an HD Drosophila model. $^{32}$

The two major targets of cAMP are Epac, which is a guanine nucleotide exchange factor and protein kinase $A(P K A)^{64}$ (Figure 3). The regulation of autophagy by CAMP was found to be mediated through Epac, and not through PKA, as an Epacspecific cAMP analogue 8-CPT-2-Me-cAMP retarded the clearance of autophagy substrates whereas the PKA-specific cAMP analogue 6-Bnz-cAMP had no effect. ${ }^{32}$ Activation of Epac by increased intracellular cAMP levels activates Rap2B, a small G-protein, which subsequently activates PLC- $\varepsilon$, and this established pathway is well conserved in various mammalian cell lines. ${ }^{32,65}$ Autophagy was induced by a dominant-negative Rap2B, which also abrogated the inhibitory effects of the Epac-specific cAMP analogue 8-CPT-2-MecAMP, suggesting that Rap2B is a downstream autophagy regulator of Epac. ${ }^{32}$ Furthermore, overexpression of PLC- $\varepsilon$ inhibited autophagy and retarded the clearance of autophagy substrates. $^{32}$ Activation of PLC- $\varepsilon$ hydrolyzes phosphatidylinositol 4,5-bisphosphate to form $\mathrm{IP}_{3}$ and diacylglycerol. Thus, the link from cAMP to Epac to Rap2B to PLC- $\varepsilon$ culminating on the generation of $\mathrm{IP}_{3}$ was consistent with our earlier findings where elevated intracellular $\mathrm{IP}_{3}$ levels were shown to negatively regulate autophagy ${ }^{30}$ (Figures 2 and 3). Indeed, overexpression of cytosolic $\mathrm{IP}_{3}$ kinase $A$, which lowers $\mathrm{IP}_{3}$ levels by phosphorylating it to inositol 1,3,4,5-tetrakisphosphate $\left(\mathrm{IP}_{4}\right),{ }^{66}$ enhanced the clearance of autophagy substrates. $^{32}$

Regulation of autophagy by reduced intracellular $\mathrm{IP}_{3}$ levels is likely because of inactivation of the signal for $\mathrm{ER} \mathrm{Ca}^{2+}$ release, as raised cytosolic $\mathrm{IP}_{3}$ levels binds to its receptors $\left(\mathrm{IP}_{3} \mathrm{R}\right)$ on the $\mathrm{ER}$ to trigger depletion of the $\mathrm{ER} \mathrm{Ca}^{2+}$ store. $^{45}$ As a rise in cytosolic $\mathrm{Ca}^{2+}$ activates calpain, we found that the inhibitory effects of PLC- $\varepsilon$ overexpression, which generates $\mathrm{IP}_{3}$, could be abolished by a calpain inhibitor. ${ }^{32}$ Furthermore, calpain inhibition by calpastatin rescued the autophagyinhibitory effects of raised cytosolic $\mathrm{Ca}^{2+}$ induced by an L-type $\mathrm{Ca}^{2+}$ channel activator or thapsigargin. ${ }^{32}$ This links $\mathrm{IP}_{3}$ regulation of autophagy to calpain through intracytosolic $\mathrm{Ca}^{2+}$ levels. Also, overexpression of constitutively active $\mathrm{m}$-calpain completely abolished the protective effects of verapamil (L-type $\mathrm{Ca}^{2+}$ channel blocker) and clonidine (reduces CAMP), ${ }^{32}$ suggesting that calpain is a downstream mediator of the autophagy signals converging from the L-type $\mathrm{Ca}^{2+}$ channels and the cAMP-Epac-PLC- $--\mathrm{IP}_{3}$ pathway. This creates an interesting cyclic pathway where calpain regulates autophagy through $\mathrm{G}_{\mathrm{s} \alpha}$ that signals through the cAMP-Epac-PLC- $\varepsilon-\mathrm{IP}_{3}$ pathway, which modulates calpain activity by influencing $\mathrm{Ca}^{2+}$ levels ${ }^{32}$ (Figure 3 ).

\section{Neurodegeneration, Excitotoxicity and Autophagy}

$\mathrm{Ca}^{2+}$ excitotoxicity results from excessive neuronal excitation by the neurotransmitter glutamate, leading to cell stress or death primarily because of $\mathrm{Ca}^{2+}$ influx. ${ }^{67} \mathrm{~A}$ number of studies have suggested that increased cytosolic $\mathrm{Ca}^{2+}$ contributing to excitotoxicity may be an important mediator of a variety of neurodegenerative diseases. For example, abnormally high cytosolic $\mathrm{Ca}^{2+}$ levels were detected in cultured CA1 pyramidal neurons in transgenic HD mice expressing full-length human mutant huntingtin. ${ }^{68}$ Mutant huntingtin increased $\mathrm{Ca}^{2+}$ levels in cultured $\mathrm{HD}$ mouse neurons by potentiating the activity of NR2B subtype of $\mathrm{N}$-methyl-Daspartate receptors (NMDARs), ${ }^{69}$ class 1 metabotropic glutamate receptors (mGluR1/5) and type 1 inositol 1,4,5trisphosphate receptors $\left(\mathrm{IP}_{3} \mathrm{R} 1\right)^{70}$ (Figure 4). Stimulation of glutamate receptors (NMDARs and mGluR1/5) and $I P_{3} R 1$ causes excessive $\mathrm{Ca}^{2+}$ overload that leads to excitotoxicity in HD mouse neurons. ${ }^{67}$ Furthermore, increased intracellular $\mathrm{Ca}^{2+}$ can be toxic by activating caspases that trigger apoptosis by mitochondrial $\mathrm{Ca}^{2+}$ overload. ${ }^{69,71}$ Increased caspase activity catalyzes mutant huntingtin proteolysis, leading to generation of toxic N-terminal fragments. ${ }^{72}$ Moreover, elevated $\mathrm{Ca}^{2+}$ levels activate calpains, which has been reported by Ellerby and Gafni in the caudate of human HD brains. $^{73}$

These data suggest that autophagy is inhibited by elevated intracytosolic $\mathrm{Ca}^{2+}$ levels caused by increased influx of $\mathrm{Ca}^{2+}$ through $\mathrm{Ca}^{2+}$ channels on the cell membrane or due to depletion of the intracellular $\mathrm{Ca}^{2+}$ stores. Increased cytosolic $\mathrm{Ca}^{2+}$ inhibits autophagy by calpain activation. ${ }^{32}$ If this occurred in cells with no mTOR inhibition, then one would expect that autophagy would be inhibited. This would impair the clearance of aggregate-prone proteins, which may, in turn, augment neurodegeneration by creating a positive feedback loop resulting in more $\mathrm{Ca}^{2+}$ excitotoxicity and apoptosis (Figure 4).

\section{Other mTOR-Independent Small Molecule Regulators of Autophagy}

We have recently identified a number of small molecule enhancers and inhibitors of mTOR-independent mammalian autophagy by a chemical screening approach. ${ }^{36} \mathrm{~A}$ primary screen in yeast with 50729 compounds revealed various enhancers (small-molecule enhancers of rapamycin (SMERs)) and suppressors (small-molecule inhibitors of rapamycin (SMIRs)) of the cytostatic effects of rapamycin in yeast. A secondary screen in mammalian cells with SMERs and SMIRs, tested independently without rapamycin, identified 3 SMERs that induced autophagy and enhanced the clearance of aggregate-prone proteins. ${ }^{36}$ Interestingly, all the autophagy-inducing SMERs (SMERs 10, 18 and 28) protected against mutant huntingtin fragment toxicity in $\mathrm{HD}$ Drosophila model, ${ }^{36}$ and two of them enhanced killing of mycobacteria by primary human macrophages in models of 


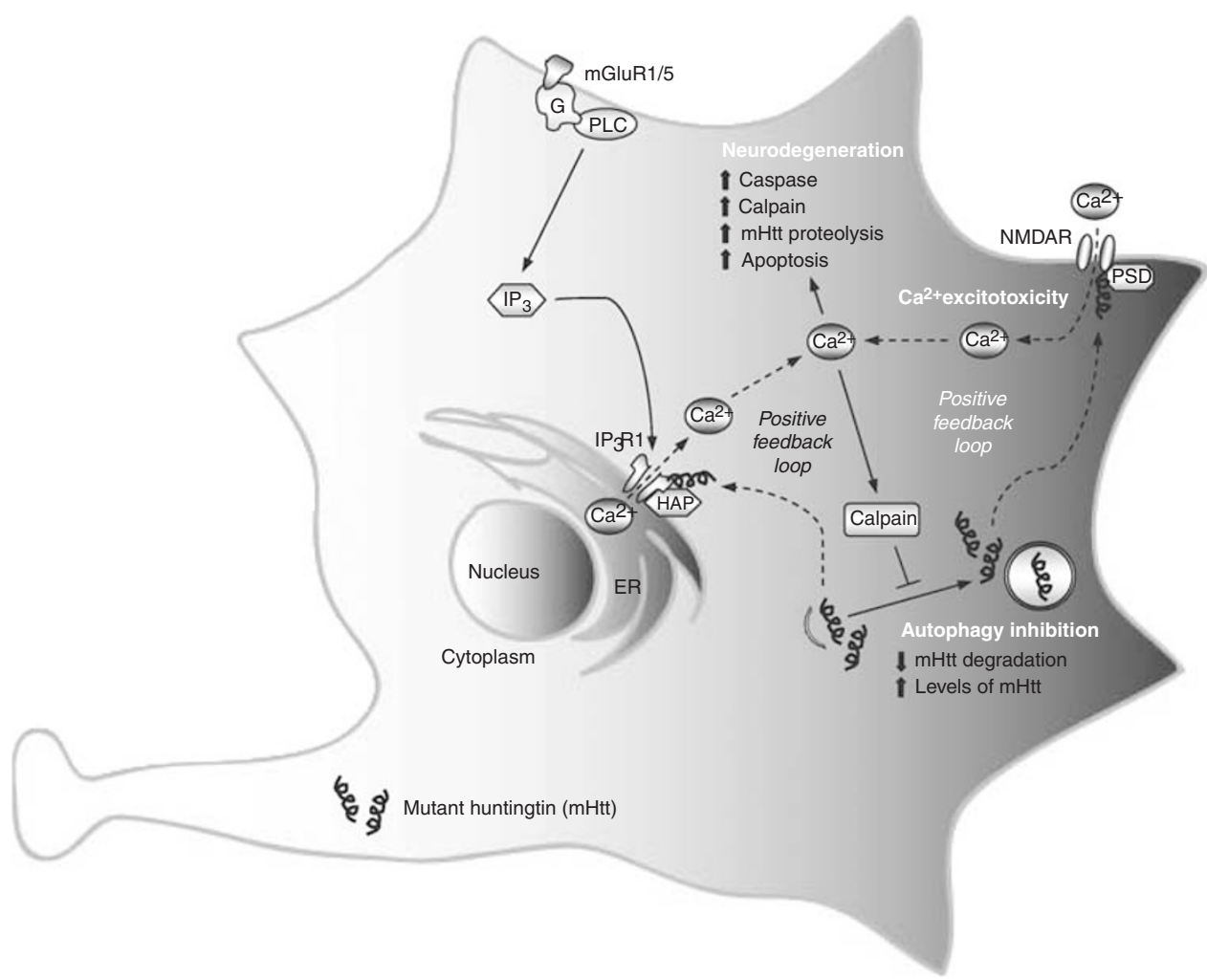

Figure $4 \mathrm{Ca}^{2+}$ excitotoxicity impairs autophagy and augments neurodegeneration. Mutant huntingtin (mhtt) associated with Huntington's disease (HD) has been suggested to cause $\mathrm{Ca}^{2+}$ excitotoxicity in neurons. Mutant huntingtin increases NMDA receptor (NMDAR) function, possibly through altered interaction with PSD95-NR1A/ NR2B complex, which results in abnormally high $\mathrm{Ca}^{2+}$ influx. Mutant huntingtin also binds to inositol 1,4,5-trisphosphate receptor $\left(I P_{3} R\right)$ on the endoplasmic reticulum (ER) through huntingtin-associated protein-1A (HAP1A). This binding of the mutant protein sensitizes $\mathrm{IP}_{3} R$ and depletes $E R \mathrm{Ca}^{2+}$ stores in response to low levels of $I P_{3}$ generated by the heterotrimeric G-protein-linked phospholipase C (PLC) signalling from the metabotrophic glutamate receptors (mGluR1/5). Increased intracytosolic $\mathrm{Ca}^{2+}$ levels activate caspases and calpains, which cleave mutant huntingtin into toxic $\mathrm{N}$-terminal fragments, thereby triggering apoptosis and augmenting neurodegeneration. Calpain activation also inhibits autophagy and impairs the clearance of mutant aggregate-prone proteins. This block in autophagy results in high levels of mutant proteins in cells, which in turn lead to more $\mathrm{Ca}^{2+}$ excitotoxicity and neurodegeneration in a positive feedback loop. This model assumes no change in mTOR activity

tuberculosis. ${ }^{74}$ Further screening of structural analogues of these SMERs identified 18 additional candidates that enhanced the clearance of aggregate-prone proteins. ${ }^{36}$

An image-based screen for autophagy inducers carried out by Yuan and coworkers ${ }^{33}$ with 480 bioactive compounds identified a number of compounds, which induced mTORindependent autophagy and reduced expanded polyQ aggregates in a cell-based assay. Their hits include fluspirilene, trifluoperazine (dopamine antagonist), pimozide, niguldipine, amiodarone, loperamide $\left(\mathrm{Ca}^{2+}\right.$ channel blockers $)$ and penitrem $\mathrm{A}$ (inhibitor of high conductance $\mathrm{Ca}^{2+}$-activated $\mathrm{K}^{+}$ channels), which provide a number of candidates for neurodegenerative disorders as most of these compounds were FDA-approved drugs. ${ }^{33}$

Another mTOR-independent autophagy enhancer is trehalose ${ }^{34}$ a disaccharide, which is also a 'chemical chaperone' because of its ability to influence protein folding through direct protein-trehalose interactions. ${ }^{75}$ Although we have shown that trehalose enhanced the clearance of mutant huntingtin and protected against pro-apoptotic insults in cells, ${ }^{34}$ it was earlier shown to be protective in HD mouse model. ${ }^{35}$ The protective properties of trehalose as an 'autophagy inducer' and 'chemical chaperone', coupled with its lack of toxicity, may be of great benefit in the treatment of neurodegenerative disorders.

\section{Downstream Targets of mTOR and mTOR-Independent Regulators}

Many of the molecular mechanisms of the autophagic machinery have been dissected in yeast, where the kinase Atg1p was shown to be required for autophagosome formation acting downstream of TOR. ${ }^{2}$ Atg 1 homologues have been reported in several species, including mammals, where there are two Atg1 homologues, UNC (uncoordinated movement)51-like kinase 1 (ULK1) and ULK2. ${ }^{76,77}$ Tooze and coworkers ${ }^{78}$ have shown that siRNA-mediated knockdown of ULK1, but not ULK2, inhibited rapamycin-induced autophagy, further suggesting a role downstream of mTOR. This is consistent with our earlier finding in which rapamycin failed to rescue neurodegeneration in Drosophila with heterozygous loss of Atg1. ${ }^{20}$ Interestingly, Neufeld and coworkers ${ }^{79}$ have shown that overexpression of Atg1 in Drosophila induced autophagy. Mizushima and coworkers ${ }^{80}$ have recently identified the focal adhesion kinase family-interacting protein of $200 \mathrm{kDa}$ (FIP200) as a murine ULK-interacting protein. ULK1 and ULK2, as well as FIP200, localized to phagophores upon starvation and FIP200 is necessary for membrane targeting and functioning of ULKs. Using FIP200-deficient MEFs, the authors have shown that autophagy induced by starvation, 
rapamycin, lithium or ceramide was impaired, as assessed by LC3 conversion. ${ }^{80}$ These interesting data suggest that FIP200 is a downstream mediator of both mTOR-dependent and mTOR-independent autophagy pathways.

Although the autophagic machinery in yeast has been extensively studied, pathways regulating mammalian autophagy are not fully understood. An important question that needs to be elucidated is how our recently described mTORindependent cyclic pathway connects to the autophagic machinery. However, we cannot exclude the possibility that this pathway may have several branching points that link to the autophagic machinery. This remains a daunting task as it is still unclear how mTOR regulates autophagy. Furthermore, the targets of various autophagy-inducing small molecules reported so far are still unknown, and the mechanisms of how they trigger autophagy require further studies. Nonetheless, the growing number of small molecule autophagy enhancers may have possible benefits for neurodegenerative disorders or other diseases where autophagy acts as a protective pathway, and may also shed light on important regulatory pathways governing autophagy in mammalian systems.

Acknowledgements. We are grateful to the MRC, Wellcome Trust (Senior Fellowship to DCR), EU Framework VI (EUROSCA) and the National Institute for Health Research Biomedical Research Centre at Addenbrooke's Hospital for funding work that we have discussed in this review.

1. Mizushima N, Levine B, Cuervo AM, Klionsky DJ. Autophagy fights disease through cellular self-digestion. Nature 2008; 451: 1069-1075.

2. Xie Z, Klionsky DJ. Autophagosome formation: core machinery and adaptations. Nat Cell Biol 2007; 9: 1102-1109.

3. Berg TO, Fengsrud M, Stromhaug PE, Berg T, Seglen PO. Isolation and characterization of rat liver amphisomes. Evidence for fusion of autophagosomes with both early and late endosomes. J Biol Chem 1998; 273: 21883-21892.

4. Levine B, Klionsky DJ. Development by self-digestion: molecular mechanisms and biological functions of autophagy. Dev Cell 2004; 6: 463-477.

5. Ohsumi Y. Molecular dissection of autophagy: two ubiquitin-like systems. Nat Rev Mol Cell Biol 2001; 2: 211-216.

6. Petiot A, Ogier-Denis E, Blommaart EF, Meijer AJ, Codogno P. Distinct classes of phosphatidylinositol $3^{\prime}$-kinases are involved in signaling pathways that control macroautophagy in HT-29 cells. J Biol Chem 2000; 275: 992-998.

7. Rubinsztein DC, Gestwicki JE, Murphy LO, Klionsky DJ. Potential therapeutic applications of autophagy. Nat Rev Drug Discov 2007; 6: 304-312.

8. Kabeya Y, Mizushima N, Ueno T, Yamamoto A, Kirisako T, Noda T et al. LC3, a mammalian homologue of yeast Apg8p, is localized in autophagosome membranes after processing. EMBO J 2000; 19: 5720-5728.

9. Seglen PO, Gordon PB. Amino acid control of autophagic sequestration and protein degradation in isolated rat hepatocytes. J Cell Biol 1984; 99: 435-444.

10. Maiuri MC, Zalckvar E, Kimchi A, Kroemer G. Self-eating and self-killing: crosstalk between autophagy and apoptosis. Nat Rev Mol Cell Biol 2007; 8: 741-752.

11. Ross CA, Poirier MA. Protein aggregation and neurodegenerative disease. Nat Med 2004 10 (Suppl): S10-S17.

12. Shao J, Diamond MI. Polyglutamine diseases: emerging concepts in pathogenesis and therapy. Hum Mol Genet 2007; 16 Spec No. 2 R115-R123.

13. Haass $C$, Selkoe DJ. Soluble protein oligomers in neurodegeneration: lessons from the Alzheimer's amyloid beta-peptide. Nat Rev Mol Cell Biol 2007; 8: 101-112.

14. Ross CA, Poirier MA. What is the role of protein aggregation in neurodegeneration? Nat Rev Mol Cell Biol 2005; 6: 891-898.

15. Arrasate M, Mitra S, Schweitzer ES, Segal MR, Finkbeiner S. Inclusion body formation reduces levels of mutant huntingtin and the risk of neuronal death. Nature 2004; 431: 805-810.

16. Rubinsztein DC. The roles of intracellular protein-degradation pathways in neurodegeneration. Nature 2006; 443: 780-786.

17. Ravikumar B, Duden R, Rubinsztein DC. Aggregate-prone proteins with polyglutamine and polyalanine expansions are degraded by autophagy. Hum Mol Genet 2002; 11 1107-1117.
18. Ravikumar B, Vacher C, Berger Z, Davies JE, Luo S, Oroz LG et al. Inhibition of mTOR induces autophagy and reduces toxicity of polyglutamine expansions in fly and mouse models of Huntington disease. Nat Genet 2004; 36: 585-595.

19. Webb JL, Ravikumar B, Atkins J, Skepper JN, Rubinsztein DC. Alpha-Synuclein is degraded by both autophagy and the proteasome. J Biol Chem 2003; 278: 25009-25013.

20. Berger Z, Ravikumar B, Menzies FM, Oroz LG, Underwood BR, Pangalos MN et al. Rapamycin alleviates toxicity of different aggregate-prone proteins. Hum Mol Genet 2006; 15: 433-442.

21. Fornai $F$, Longone $\mathrm{P}$, Cafaro L, Kastsiuchenka O, Ferrucci M, Manca ML et al. Lithium delays progression of amyotrophic lateral sclerosis. Proc Natl Acad Sci USA 2008; 105: 2052-2057.

22. Shibata M, Lu T, Furuya T, Degterev A, Mizushima N, Yoshimori T et al. Regulation of intracellular accumulation of mutant Huntingtin by Beclin 1. J Biol Chem 2006; 281: 14474-14485.

23. Cuervo AM, Stefanis L, Fredenburg R, Lansbury PT, Sulzer D. Impaired degradation of mutant alpha-synuclein by chaperone-mediated autophagy. Science 2004; 305: 1292-1295.

24. Martinez-Vicente M, Talloczy Z, Kaushik S, Massey AC, Mazzulli J, Mosharov EV et al. Dopamine-modified alpha-synuclein blocks chaperone-mediated autophagy. J Clin Invest 2008; 118: 777-788.

25. Hara T, Nakamura K, Matsui M, Yamamoto A, Nakahara Y, Suzuki-Migishima R et al. Suppression of basal autophagy in neural cells causes neurodegenerative disease in mice. Nature 2006; 441: 885-889.

26. Komatsu M, Waguri S, Chiba T, Murata S, Iwata JI, Tanida I et al. Loss of autophagy in the central nervous system causes neurodegeneration in mice. Nature 2006; 441 . $880-884$.

27. Pandey UB, Nie Z, Batlevi Y, McCray BA, Ritson GP, Nedelsky NB et al. HDAC6 rescues neurodegeneration and provides an essential link between autophagy and the UPS. Nature 2007; 447: 859-863.

28. Ravikumar B, Berger Z, Vacher C, O'Kane CJ, Rubinsztein DC. Rapamycin pre-treatment protects against apoptosis. Hum Mol Genet 2006; 15: 1209-1216

29. Ravikumar B, Stewart A, Kita H, Kato K, Duden R, Rubinsztein DC. Raised intracellular glucose concentrations reduce aggregation and cell death caused by mutant huntingtin exon 1 by decreasing mTOR phosphorylation and inducing autophagy. Hum Mol Genet 2003; 12: 985-994.

30. Sarkar S, Floto RA, Berger Z, Imarisio S, Cordenier A, Pasco M et al. Lithium induces autophagy by inhibiting inositol monophosphatase. J Cell Biol 2005; 170: 1101-1111.

31. Sarkar S, Krishna G, Imarisio S, Saiki S, O'Kane CJ, Rubinsztein DC. A rational mechanism for combination treatment of Huntington's disease using lithium and rapamycin. Hum Mol Genet 2008; 17: 170-178.

32. Williams A, Sarkar S, Cuddon P, Ttofi EK, Saiki S, Siddiqi FH et al. Novel targets for Huntingtin's disease in an mTOR-independent autophagy pathway. Nat Chem Biol 2008; 4: 295-305.

33. Zhang L, Yu J, Pan H, Hu P, Hao Y, Cai W et al. Small molecule regulators of autophagy identified by an image-based high-throughput screen. Proc Natl Acad Sci USA 2007; 104: 19023-19028.

34. Sarkar S, Davies JE, Huang Z, Tunnacliffe A, Rubinsztein DC. Trehalose, a novel mTORindependent autophagy enhancer, accelerates the clearance of mutant huntingtin and alpha-synuclein. J Biol Chem 2007; 282: 5641-5652.

35. Tanaka M, Machida Y, Niu S, Ikeda T, Jana NR, Doi $\mathrm{H}$ et al. Trehalose alleviates polyglutamine-mediated pathology in a mouse model of Huntington disease. Nat Med 2004; 10: 148-154.

36. Sarkar S, Perlstein EO, Imarisio S, Pineau S, Cordenier A, Maglathlin RL et al. Small molecules enhance autophagy and reduce toxicity in Huntington's disease models. Nat Chem Biol 2007; 3: 331-338

37. Noda T, Ohsumi Y. Tor, a phosphatidylinositol kinase homologue, controls autophagy in yeast. J Biol Chem 1998; 273: 3963-3966.

38. Sarbassov DD, Ali SM, Sabatini DM. Growing roles for the mTOR pathway. Curr Opin Cell Biol 2005; 17: 596-603.

39. Kim DH, Sarbassov DD, Ali SM, King JE, Latek RR, Erdjument-Bromage $\mathrm{H}$ et al. mTOR interacts with raptor to form a nutrient-sensitive complex that signals to the cell growth machinery. Cell 2002; 110: 163-175.

40. Kim DH, Sarbassov DD, Ali SM, Latek RR, Guntur KV, Erdjument-Bromage $\mathrm{H}$ et al. GbetaL, a positive regulator of the rapamycin-sensitive pathway required for the nutrientsensitive interaction between raptor and mTOR. Mol Cell 2003; 11: 895-904

41. Cao Y, Espinola JA, Fossale E, Massey AC, Cuervo AM, MacDonald ME et al. Autophagy is disrupted in a knock-in mouse model of juvenile neuronal ceroid lipofuscinosis. J Biol Chem 2006; 281: 20483-20493.

42. King MA, Hands S, Hafiz F, Mizushima N, Tolkovsky AM, Wyttenbach A. Rapamycin inhibits polyglutamine aggregation independently of autophagy by reducing protein synthesis. Mol Pharmacol 2008; 73: 1052-1063.

43. Williams RS, Cheng L, Mudge AW, Harwood AJ. A common mechanism of action for three mood-stabilizing drugs. Nature 2002; 417: 292-295.

44. Hallcher LM, Sherman WR. The effects of lithium ion and other agents on the activity of myo-inositol-1-phosphatase from bovine brain. J Biol Chem 1980; 255: 10896-10901.

45. Berridge MJ. Inositol trisphosphate and calcium signalling. Nature 1993; 361: 315-325 
46. Criollo A, Maiuri MC, Tasdemir E, Vitale I, Fiebig AA, Andrews D et al. Regulation of autophagy by the inositol trisphosphate receptor. Cell Death Differ 2007; 14 1029-1039.

47. Berridge MJ, Downes CP, Hanley MR. Neural and developmental actions of lithium: a unifying hypothesis. Cell 1989; 59: 411-419.

48. Sarkar $S$, Rubinsztein DC. Inositol and $\mathrm{IP}_{3}$ levels regulate autophagy: biology and therapeutic speculations. Autophagy 2006; 2: 132-134.

49. Cleary C, Linde JA, Hiscock KM, Hadas I, Belmaker RH, Agam G et al. Antidepressive-like effects of rapamycin in animal models: implications for mTOR inhibition as a new target for treatment of affective disorders. Brain Res Bull 2008; 76: 469-473.

50. Rowe MK, Chuang DM. Lithium neuroprotection: molecular mechanisms and clinical implications. Expert Rev Mol Med 2004; 6: 1-18.

51. Berger Z, Ttofi EK, Michel CH, Pasco M, Tenant S, Rubinsztein DC et al. Lithium rescues toxicity of aggregate-prone proteins in Drosophila by perturbing Wnt pathway. Hum $\mathrm{Mol}$ Genet 2005; 14: 3003-3011.

52. Carmichael J, Sugars KL, Bao YP, Rubinsztein DC. Glycogen synthase kinase-3beta inhibitors prevent cellular polyglutamine toxicity caused by the Huntington's disease mutation. J Biol Chem 2002; 277: 33791-33798.

53. Shaltiel G, Shamir A, Shapiro J, Ding D, Dalton E, Bialer M et al. Valproate decreases inositol biosynthesis. Biol Psychiatry 2004; 56: 868-874.

54. Inoki K, Ouyang H, Zhu T, Lindvall C, Wang Y, Zhang X et al. TSC2 integrates Wnt and energy signals via a coordinated phosphorylation by AMPK and GSK3 to regulate cell growth. Cell 2006; 126: 955-968.

55. Gordon PB, Holen I, Fosse M, Rotnes JS, Seglen PO. Dependence of hepatocytic autophagy on intracellularly sequestered calcium. J Biol Chem 1993; 268: 26107-26112.

56. Triggle DJ. Calcium channel antagonists: clinical uses-past, present and future. Biochem Pharmacol 2007; 74: 1-9.

57. Bahro M, Pfeifer U. Short-term stimulation by propranolol and verapamil of cardiac cellular autophagy. J Mol Cell Cardiol 1987; 19: 1169-1178.

58. Hayashi S, Horie M, Okada Y. Ionic mechanism of minoxidil sulfate-induced shortening of action potential durations in guinea pig ventricular myocytes. J Pharmacol Exp Ther 1993; 265: $1527-1533$

59. Goll DE, Thompson VF, Li H, Wei W, Cong J. The calpain system. Physiol Rev 2003; 83 731-801.

60. Sato-Kusubata K, Yajima Y, Kawashima S. Persistent activation of Gsalpha through limited proteolysis by calpain. Biochem J 2000; 347: 733-740.

61. Hoyer-Hansen M, Bastholm L, Szyniarowski P, Campanella M, Szabadkai G, Farkas T et al. Control of macroautophagy by calcium, calmodulin-dependent kinase kinase-beta, and bcl-2. Mol Cell 2007; 25: 193-205.

62. Osborne NN. Inhibition of cAMP production by alpha 2-adrenoceptor stimulation in rabbit retina. Brain Res 1991; 553: 84-88.

63. Felsen D, Ernsberger P, Sutaria PM, Nejat RJ, Nguyen $\mathrm{P}$, May $\mathrm{M}$ et al. Identification, localization and functional analysis of imidazoline and alpha adrenergic receptors in canine prostate. J Pharmacol Exp Ther 1994; 268: 1063-1071.
64. Kopperud R, Krakstad C, Selheim F, Doskeland SO. cAMP effector mechanisms. Nove twists for an 'old' signaling system. FEBS Lett 2003; 546: 121-126.

65. Kelley GG, Reks SE, Ondrako JM, Smrcka AV. Phospholipase C(epsilon): a novel Ras effector. EMBO J 2001; 20: 743-754.

66. Schell MJ, Erneux C, Irvine RF. Inositol 1,4,5-trisphosphate 3-kinase A associates with F-actin and dendritic spines via its N terminus. J Biol Chem 2001; 276: 37537-37546.

67. Raymond LA. Excitotoxicity in Huntington disease. Clin Neurosci Res 2003; 3: 121-128.

68. Hodgson JG, Agopyan N, Gutekunst CA, Leavitt BR, LePiane F, Singaraja R et al. A YAC mouse model for Huntington's disease with full-length mutant huntingtin, cytoplasmic toxicity, and selective striatal neurodegeneration. Neuron 1999; 23: 181-192.

69. Zeron MM, Hansson O, Chen N, Wellington CL, Leavitt BR, Brundin P et al. Increased sensitivity to $\mathrm{N}$-methyl-D-aspartate receptor-mediated excitotoxicity in a mouse model of Huntington's disease. Neuron 2002; 33: 849-860.

70. Tang TS, Tu H, Chan EY, Maximov A, Wang Z, Wellington $\mathrm{CL}$ et al. Huntingtin and huntingtin-associated protein 1 influence neuronal calcium signaling mediated by inositol$(1,4,5)$ triphosphate receptor type 1. Neuron 2003; 39: 227-239.

71. Tang TS, Slow E, Lupu V, Stavrovskaya IG, Sugimori M, Llinás $\mathrm{R}$ et al. Disturbed $\mathrm{Ca}^{2+}$ signaling and apoptosis of medium spiny neurons in Huntington's disease. Proc Natl Acad Sci USA 2005; 102: 2602-2607.

72. Wellington CL, Ellerby LM, Hackam AS, Margolis RL, Trifiro MA, Singaraja R et al. Caspase cleavage of gene products associated with triplet expansion disorders generates truncated fragments containing the polyglutamine tract. J Biol Chem 1998; 273 9158-9167.

73. Gafni J, Ellerby LM. Calpain activation in Huntington's disease. J Neurosci 2002; 22 4842-4849.

74. Floto RA, Sarkar S, Perlstein EO, Kampmann B, Schreiber SL, Rubinsztein DC. Small molecule enhancers of rapamycin-induced TOR inhibition promote autophagy, reduce toxicity in Huntington's disease models and enhance killing of mycobacteria by macrophages. Autophagy 2007; 3: 620-622.

75. Chen $Q$, Haddad GG. Role of trehalose phosphate synthase and trehalose during hypoxia: from flies to mammals. J Exp Biol 2004; 207: 3125-3129.

76. Yan J, Kuroyanagi H, Kuroiwa A, Matsuda Y, Tokumitsu H, Tomoda T et al. Identification of mouse ULK, a novel protein kinase structurally related to $C$. elegans UNC-51. Biochem Biophys Res Commun 1998; 246: 222-227.

77. Yan J, Kuroyanagi H, Tomemori T, Okazaki N, Asato K, Matsuda Y et al. Mouse ULK2, a novel member of the UNC-51-like protein kinases: unique features of functional domains. Oncogene 1999; 18: 5850-5859.

78. Chan EY, Kir S, Tooze SA. siRNA screening of the kinome identifies ULK1 as a multidomain modulator of autophagy. J Biol Chem 2007; 282: 25464-25474.

79. Scott RC, Juhasz G, Neufeld TP. Direct induction of autophagy by Atg1 inhibits cell growth and induces apoptotic cell death. Curr Biol 2007; 17: 1-11.

80. Hara T, Takamura A, Kishi C, lemura S, Natsume T, Guan JL et al. FIP200, a ULKinteracting protein, is required for autophagosome formation in mammalian cells. $\mathrm{J}$ Cell Biol 2008; 181: 497-510. 